\title{
ApoER2 Function in the Establishment and Maintenance of Retinal Synaptic Connectivity
}

\author{
Justin H. Trotter, ${ }^{1}$ Martin Klein, ${ }^{4}$ Umesh K. Jinwal, ${ }^{2}$ Jose F. Abisambra, ${ }^{3}$ Chad A. Dickey, ${ }^{3}$ Jeremy Tharkur, ${ }^{1}$ \\ Irene Masiulis, ${ }^{5}$ Jindong Ding, ${ }^{6}$ Kirsten G. Locke, ${ }^{4}$ Catherine Bowes Rickman, ${ }^{6}$ David G. Birch ${ }^{4}$ Edwin J. Weeber, ${ }^{1}$ \\ and Joachim Herz ${ }^{5}$ \\ ${ }^{1}$ Molecular Pharmacology and Physiology, ${ }^{2}$ Department of Pharmaceutical Sciences, and ${ }^{3}$ Department of Molecular Medicine, USF Health Byrd Alzheimer's \\ Institute, University of South Florida, Tampa, Florida 33613, ${ }^{4}$ Retina Foundation of the Southwest, Dallas, Texas 75231 , ${ }^{5}$ Departments of Molecular \\ Genetics, Neuroscience, Neurology and Neurotherapeutics, University of Texas Southwestern Medical Center at Dallas, Dallas, Texas 75390, and \\ ${ }^{6}$ Department of Ophthalmology, Duke University Medical Center, Durham, North Carolina 27710
}

The cellular and molecular mechanisms responsible for the development of inner retinal circuitry are poorly understood. Reelin and apolipoprotein $\mathrm{E}$ (apoE), ligands of apoE receptor 2 (ApoER2), are involved in retinal development and degeneration, respectively. Here we describe the function of ApoER2 in the developing and adult retina. ApoER2 expression was highest during postnatal inner retinal synaptic development and was considerably lower in the mature retina. Both during development and in the adult, ApoER2 was expressed by A-II amacrine cells. ApoER2 knock-out (KO) mice had rod bipolar morphogenic defects, altered A-II amacrine dendritic development, and impaired rod-driven retinal responses. The presence of an intact ApoER2 NPxY motif, necessary for binding Disabled-1 and transducing the Reelin signal, was also necessary for development of the rod bipolar pathway, while the alternatively spliced exon 19 was not. Mice deficient in another Reelin receptor, very low-density lipoprotein receptor (VLDLR), had normal rod bipolar morphology but altered A-II amacrine dendritic development. VLDLR KO mice also had reductions in oscillatory potentials and delayed synaptic response intervals. Interestingly, age-related reductions in rod and cone function were observed in both ApoER2 and VLDLR KOs. These results support a pivotal role for ApoER2 in the establishment and maintenance of normal retinal synaptic connectivity.

\section{Introduction}

Reelin is a large secreted glycoprotein that binds to the lipoprotein receptors apolipoprotein E receptor 2 (ApoER2) and very low-density lipoprotein receptor (VLDLR) (Hiesberger et al., 1999). Following ligand binding, the adaptor protein Disabled-1 (Dab1) associates with receptor C-terminal NPxY motifs, is tyrosine phosphorylated by members of the Srcfamily kinases, and transduces the Reelin signal downstream (Benhayon et al., 2003). Reelin signaling through these receptors is required for a range of processes in the developing and adult brain, including neuronal migration (Hiesberger et al., 1999; Andrade et al., 2007), dendritic development (Niu et al., 2004), and synaptic plasticity (Weeber et al., 2002; Beffert et al., 2005; Beffert et al., 2006b).

\footnotetext{
Received June 20, 2011; revised July 28, 2011; accepted Aug. 16, 2011.

Author contributions: J.H.T., D.G.B., and J.H. designed research; J.H.T., M.K., U.K.J., J.F.A., C.A.D., J.T., I.M., and K.G.L. performed research; I.M., J.D., C.B.R., and E.J.W. contributed unpublished reagents/analytic tools; J.H.T., M.K., D.G.B., E.J.W., and J.H. analyzed data; J.H.T., E.J.W., and J.H. wrote the paper.

This work was supported by grants from the National Institutes of Health, the American Health Assistance Foundation, the Perot Family Foundation, the Consortium for Frontotemporal Dementia Research, Sonderforschungsbereich 780, and the Humboldt Foundation. We thank Priscilla Rodriguez, Hui-Chuan Reyna, Wen-Ling Niu, Issac Rocha, lan Rusiana, and Melinda Peters for technical assistance; David M. Sherry (University of Oklahoma) for experimental advice and antibodies; Brian W. Howell (State University of New York Upstate Medical University) for the Dab1 B3 antibody; and Mildred Acevedo-Duncan (University of South Florida) for the PKC $\alpha$ antibody.

Correspondence should be addressed to Dr. Joachim Herz, University of Texas Southwestern Medical Center at Dallas, 5323 Harry Hines Boulevard, Dallas, Texas 75390-9046. E-mail: joachim.herz@utsouthwestern.edu. DOI:10.1523/JNEUROSCI.3135-11.2011

Copyright $\odot 2011$ the authors $\quad 0270-6474 / 11 / 3114413-11 \$ 15.00 / 0$
}

Mice carrying null mutations in Reln and Dab1 have impaired neuronal migration during development resulting in severe brain lamination defects (D’Arcangelo et al., 1995; Sheldon et al., 1997). While Dab1 and Reelin mutant mice do not have alterations in neuronal positioning in the retina, they do have abnormal rod bipolar cell morphology and survival, A-II amacrine synapse structure, and synaptic connectivity (Rice et al., 2001). In the developing and adult retinas, Dab1 expression is mostly restricted to A-II amacrine cells, while Reelin is expressed by some amacrine cells, cone bipolar cells, and retinal ganglion cells (Rice et al., 2001). In light of the cell-specific expression of Reelin and Dab1 in the retina and the mild retinal phenotype in mutant mice, the retina may provide an ideal model for further genetic dissection of the Reelin signaling pathway and exploration of mechanisms important for the development and maintenance of retinal circuitry.

Age-related macular degeneration (AMD) is a late-onset, multifactorial neurodegenerative disease of the retina, which shares numerous risk factors with Alzheimer's disease, particularly association with certain Apoe alleles (encoding apolipoprotein E, apoE) (Baird et al., 2004; Malek et al., 2005; Baird et al., 2006). ApoE plays an essential role in serum cholesterol homeostasis by mediating transport of lipids and cholesterol into cells (Kesaniemi et al., 1987). Similar to Reelin, ApoE acts via lipoprotein receptors to modulate a variety of physiological processes. Mice expressing human $a p o E$ alleles and fed high-fat, highcholesterol diets demonstrate differential susceptibility to AMD- 
like characteristics, such as neovascularization and retinal degeneration (Malek et al., 2005). These events are also observed in VLDLR KO mice without dietary modifications ( $\mathrm{Hu}$ et al., 2008), which suggests that diet and apoE genotype may directly impact the signaling integrity of VLDLR and other lipoprotein receptors. The relationship between $a p o E$ alleles and retinal pathology underscores the importance of understanding the function of apoE receptors in the normal and diseased retina. The basic function of VLDLR in the retina has been difficult to determine, as mice deficient in VLDLR develop pervasive choroidal neovascularization and subsequent retinal degeneration at a young age (Heckenlively et al., 2003; Li et al., 2007; Hu et al., 2008). Unlike VLDLR, the role of ApoER2 in the retina has not been investigated in detail.

In the present study, we report a role for ApoER2 in the development of the rod bipolar pathway and establishment of synaptic connectivity. In addition, we differentiate between the contributions of ApoER2 and VLDLR to both the development and maintenance of retinal synaptic connectivity with age. In particular, understanding the mechanisms that guide retinal synaptic development may provide new therapeutic targets for the treatment of retinal diseases where significant synaptic degeneration and/or remodeling occur.

\section{Materials and Methods}

Mice. Apoer 2 and VLDLR null mice were raised from stocks originally created through targeted-deletion of each individual gene (Trommsdorff et al., 1999). Apoer2-EIG (NPxY mutant) and Apoer $2 \Delta$ exon 19 mice were generated as described previously (Beffert et al., 2005; Beffert et al., 2006b). Reeler mice (B6C3Fe a/a-Reln; Jackson Laboratories) were generated by heterozygous crosses and were maintained for extended periods of time by providing moist food on the floor of the cage. Wild-type $129 \times \mathrm{C} 57 \mathrm{BL} / 6$ hybrid and C57BL/6 male and female mice were bred in house and maintained on $12 \mathrm{~h}$ light/dark cycles. The animals were fed a standard rodent chow diet (Diet 7001; Harlan Teklad) and water ad libitum. No sexual dimorphism of phenotype was observed. For most experiments, mice were grouped as young ( $3-5$ months old) or middle-aged (10-14 months). For biochemical and histological analysis, mice were also used at postnatal day 7 (P7), P12, P20, and P28. All procedures were performed in accordance with the protocols approved by the Institutional Animal Care and Use Committees of the University of Texas Southwestern Medical Center at Dallas and the University of South Florida.

Western blot analysis. Mice were killed by isoflurane exposure, and eyes were quickly dissected. Anterior segments were removed, and the posterior eyecup was placed in ice-cold PBS followed by isolation of the retina under a dissecting microscope. Specifically, retinas from P7, P12, P20, and P28 mice were isolated. Retinas were frozen on dry ice and stored at $-80^{\circ} \mathrm{C}$ until processing. Radioimmunoprecipitation assay buffer (containing $20 \mathrm{~mm}$ Tris-HCl, pH 7.5, $150 \mathrm{~mm} \mathrm{NaCl}, 1$ mm Na 2 EDTA, $1 \mathrm{~mm}$ EGTA, $1 \%$ NP-40, and $1 \%$ sodium deoxycholate) supplemented with protease inhibitor cocktail (P8430; Sigma) was added to the retinas, followed by sonication and centrifugation at $20,000 \times g$ for $20 \mathrm{~min}$. Supernatants were saved, and protein concentrations were determined using the BCA assay (23225; Pierce). After normalizing protein concentration, Laemmli sample buffer (with 5\% 2-mercaptoethanol) was added, and samples were heated at $95^{\circ} \mathrm{C}$ for $5 \mathrm{~min}$. Proteins $(10 \mu \mathrm{g})$ were separated with $4-15 \%$ w/v precast gels (456-1093; Bio-Rad) and then transferred to PVDF membrane. Following blocking with $5 \%$ bovine serum albumin (BSA) or milk in TBST, membranes were incubated with the appropriate primary antibody, including anti-ApoER2 (2561; J. Herz lab; 1:1000), Dab1 (Andre Goffinet, Dab1 E1 mAb; 1:1000), Reelin (MAB5364; Millipore Bioscience Research Reagents; 1:1000), or GADPH (Cell Signaling Technology; $1: 1000$ ) overnight at $4^{\circ} \mathrm{C}$. Membranes were washed and then incubated with corresponding HRP-conjugated secondary antibodies (anti-Mouse IgG, NA931V; anti-Rabbit IgG, NA934V; GE Healthcare).
Blots were developed with an enhanced chemiluminescence detection kit (34077; Pierce) and detected using x-ray film. Film was scanned and processed using Adobe Photoshop to adjust brightness and contrast. Four different retinas were used per age group, and all blots were performed twice. Quantification was performed as described previously (Jinwal et al., 2011).

Immunohistochemistry. Fixed eyecups were obtained for mice at early postnatal stages (P7, P12, P20, and P28), as well as from 3- to 5-monthold and 10- to 14-month-old mice. All immunohistochemistry experiments were performed on a minimum of four eyes from four different mice (per genotype), and at least three retinal sections were used per eyecup. Following anesthesia, mice were transcardially perfused with saline solution, followed by $4 \%$ paraformaldehyde (PFA). Eyes were enucleated, anterior segments were removed, and eyecups were postfixed in $4 \%$ PFA overnight at $4^{\circ} \mathrm{C}$. For mice younger than 1 month, eyes were immediately removed following decapitation, and posterior eyecups were immersion-fixed overnight $4^{\circ} \mathrm{C}$. Following fixation, eyecups were incubated in a graded sucrose series (10, 20, and 30\%) in $0.1 \mathrm{M}$ PBS. Eyes were then embedded in OCT, vertically sectioned using a cryostat at 12 $\mu \mathrm{m}$ thickness, mounted on positively charged slides, and stored at $-80^{\circ} \mathrm{C}$ until use. For immunohistochemistry, blocking buffer contained $5 \%$ normal donkey serum (NDS), $2 \%$ BSA, $0.1 \%$ sodium azide, and $0.2 \%$ or $0.5 \%$ Triton X-100 in 0.1 m PBS. For primary and secondary antibody solutions, NDS was omitted. The following primary antibodies were used in different combinations: anti-GlyT-1 (Millipore; 1:1000), anti-Dab1 (B3; Brian Howell; 1:1000), anti-ApoER2 (2561; J. Herz lab; 1:100), and anti-PKC $\alpha$ (sc-208; Santa Cruz Biotechnology; 1:100). For triple labeling or labeling two proteins with antibodies produced in the same species, the first antibody was used (antigen with lowest abundance and/or weakest antibody) followed by incubation with the first corresponding dyeconjugated, secondary antibody. Then the sections were washed and incubated with the second same-species primary antibody at room temperature for $1 \mathrm{~h}$, followed by detection with a secondary antibody conjugated with a different dye than the previously used secondary antibodies for $1 \mathrm{~h}$. Labeling was performed individually for all antibodies to ensure signal specificity, and controls were performed by omitting primary antibodies or using appropriate knock-out retinas when possible. For all other experiments, secondary antibodies (donkey anti-rabbit/mouse Alexa-fluor conjugates; Invitrogen) were applied at 1:200 for $1 \mathrm{~h}$ at room temperature. Prolong with or without DAPI (for visualization of nuclei; Invitrogen) was applied to sections and slides were coverslipped. Images were taken using a Zeiss upright fluorescence microscope (AxioImager Z1) and were processed using AxioVisionLE software (Zeiss) and Adobe Photoshop. At least two images were taken from the central to midperipheral retina. Representative images were included for publication. For images taken using $63 \times$ and $100 \times$ oil-immersion objectives, an ApoTome was always used with medium filtering and noise reduction (level 2-3). $Z$ stacks were generated by optical sectioning every $0.25 \mu \mathrm{m}$, and merged images (maximal image projections) were produced, containing $2.50 \mu \mathrm{m}$ in the $z$ dimension. Images were minimally processed using Adobe Photoshop, with only brightness and contrast being adjusted equally within experimental groups.

Colocalization analysis was performed using the Axiovision Colocalization Module (Zeiss). Dab1 and ApoER2 immunostaining was visualized using a $20 \times$ Apochrome objective. Regions of interest contained only the inner plexiform layer (IPL) and inner nuclear layer (INL), where specific Dab1 labeling occurred. Image brightness was adjusted to eliminate background fluorescence. Thresholds were first established by determining the highest gating threshold at which colocalization did not occur in ApoER2 KO sections (i.e., containing pixels of tissue autofluorescence colocalized with Dab1). Threshold settings were further manually defined to restrict colocalization to Dab1-positive, A-II amacrine cells. Scatter plots were generated and both Pearson $(>0)$ and Mander coefficients $(>0.9)$ were noted.

Electroretinography. Eyes were dilated by topical application of hyoscine $0.25 \%$ and dark adapted overnight. Dilation was reinforced before testing. Mice were anesthetized by intraperitoneal injection of ketamine/ xylazine and placed between heating pads to ensure stable internal temperature. Application of Refresh Celluvisc (Allergan) prevented drying 


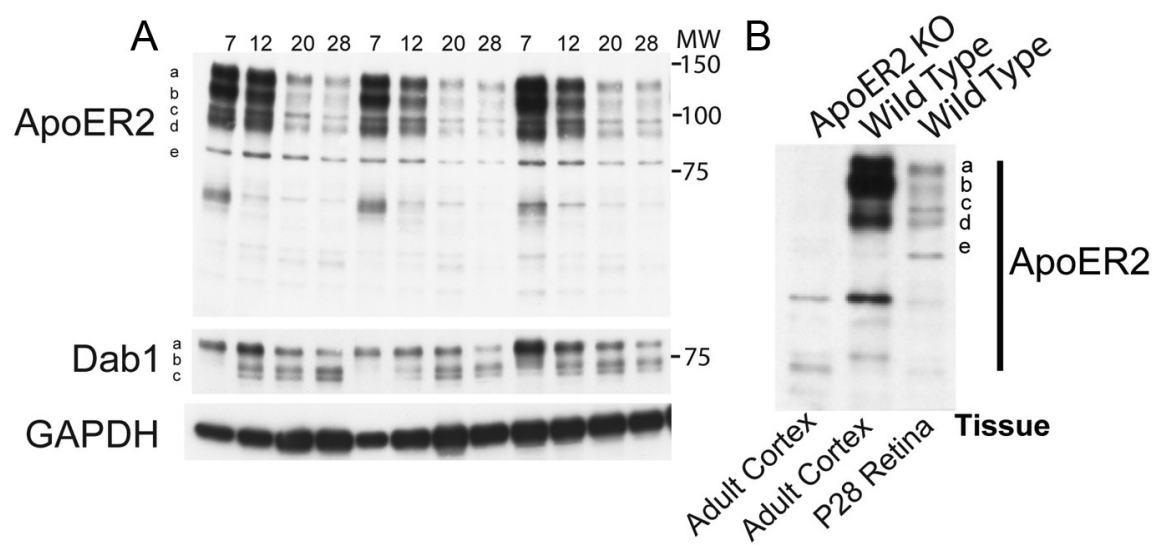

Figure 1. Expression of ApoER2 in the developing retina. $A$, Retinas isolated at P7-P28 were subjected to Western blot analysis, revealing dramatic reductions in ApoER2 expression from P7 through P20. ApoER2 was found to exist in at least five forms (a-e), which all changed similarly across development. Molecular weight (MW, in kilodaltons) is indicated alongside the blots. GADPH levels revealed little difference in loading. $\boldsymbol{B}$, Antibody specificity was determined by probing cortical lysates derived from adult ApoER2 K0 and wild-type mice and comparing them to wild-type retinal lysate from P28. ApoER2 isoforms found in the adult cortex were identical to those found in the developing retina and were not found in ApoER2 KOs.

and cloudiness of the cornea. Corneas were desensitized with topical application of propocaine hydrochloride $0.5 \%$. A monopolar gold contact lens was used as an active electrode with needle electrodes in the scalp and the tail as reference and ground, respectively. Full-field electroretinograms (ERGs) were recorded from one eye following International Society for Clinical Electrophysiology of Vision standard protocol adjusted for mice. ERG recordings were performed with an Espion V2 (Diagnosys). Responses were elicited with the LED-based Espion Colordome (Diagnosys). Stimulus colors used were predefined by Diagnosys. Rod responses were elicited with a $0.19 \mathrm{scotopic} \mathrm{cd} \cdot \mathrm{s} / \mathrm{m}^{2}$ (Blue) stimulus. For standard combined responses, an $8.42 \operatorname{scotopic~} \mathrm{cd} \cdot \mathrm{s} / \mathrm{m}^{2}$ (white; $6500 \mathrm{~K}$ ) stimulus was used. Oscillatory potentials (OPs) were elicited with the same stimulus and isolated by filtering the signal with a highpass filter set to $100 \mathrm{~Hz}$ and a low-pass filter set to $300 \mathrm{~Hz}$. Mice were light adapted for $10 \mathrm{~min}$ with a $31.6 \mathrm{~cd} / \mathrm{m}^{2}$ background light. Light-adapted cone responses were elicited with a 3.89 photopic $\mathrm{cd} \cdot \mathrm{s} / \mathrm{m}^{2}$ (white; 6500 $\mathrm{K})$ stimulus on the same background.

Cone flicker responses (CFRs) were recorded with a $31 \mathrm{~Hz}$ flicker of a 3.89 photopic $\mathrm{cd} \cdot \mathrm{s} / \mathrm{m}^{2}$ (white; $6500 \mathrm{~K}$ ) stimulus on the background. At least 10 responses ( 50 for flicker responses) per step were recorded and averaged by computer.

Funduscopy and fluorescein angiography. The in vivo fundus photography and fluorescein angiography (FA) were performed using a modified hand-held Kowa RC-2 camera (Hoffman et al., 2004). Images were performed without anesthesia and always on a different day than the electroretinography to minimize corneal artifacts and to avoid flash exposure before the electroretinography. Fundus photographs were taken with Ektachrome 100 ISI $35 \mathrm{~mm}$ color slide film and developed with an E6 processor. Fluorescein angiographs were recorded with Tri-X 400 ISI black and white $35 \mathrm{~mm}$ film and pushed one f-stop during development to compensate for the slightly dimmer flash setting available on this camera. Both eyes were dilated twice using scopolamine hydrobromide and phenylephrine hydrochloride ophthalmic solutions, with the first set starting $12 \mathrm{~h}$ prior and another set $30 \mathrm{~min}$ before the procedure. After the color fundus photographs were taken, $0.1 \mathrm{ml}$ of fluorescein sodium $25 \%$ was injected into the peritoneum for the FA procedure.

After film development, images were digitized using a Nikon CoolScan V film scanner. Each image was cropped down to contain only the retinal information and cleaned for dust spots and artifacts from the film surface before publication.

Data analysis. SEM was calculated where $n$ was $\geq 3$. Statistical significance was determined using the two-tailed Student's $t$ test and was considered as $\alpha \leq 0.05$.

\section{Results \\ ApoER2 expression during retinal development}

To address the role of ApoER2 in retinal development, we first determined whether ApoER2 was expressed in the retina, and whether expression differed across development from P7 to P28. Retinas were isolated from P7, P12, P20, and P28 wildtype mice $(n=4)$ and subjected to Western blot analysis. We detected five major ApoER2 bands (Fig. 1 A, a-e), which were seen at varying levels across development. The total level of ApoER2 was highest at P7, decreasing by $\sim 30 \%$ on P12, and $70 \%$ on P20 and P28. ApoER2 levels at P60 and P300 were comparable to P28 (data not shown). Quantification of individual bands revealed that ApoER2 isoforms a-e were not significantly reduced from P7 to P12, but a significant reduction was observed at P20 and P28 $(p<0.01)$. We also observed accumulation of the Dab1 isoforms b and $\mathrm{c}$ between P7 and P20 $(p<0.05)$ and a significant downregulation of Dab1 isoform a by P28 $(p<0.05)$. ApoER2 levels were also measured in cortical lysates from adult wild-type and ApoER2 KO mice. All ApoER2 bands (a-e) were detected in the wild-type cortex (Fig. $1 B$ ) at levels comparable to P7-P12 retina, suggesting that the same ApoER2 isoforms present in the adult brain are also expressed by the developing and mature retina.

A previous study failed to detect ApoER2 expression in the early postnatal retina at P3-P5 (Kurumada et al., 2007). We determined the localization of ApoER2 in the P7 retina due to its high protein expression levels and the importance of Reelin signaling in bipolar morphogenesis, which still occurs at this time point. We found that ApoER2 was enriched in subsets of amacrine and/or bipolar cells present in the INL (Fig. 2 B). Moreover, ApoER2 was highly enriched in the IPL, where it colocalized with Reelin (Fig. 2C, magnified in $E-G$ ). Lower levels of ApoER2 were detected throughout the IPL, INL, and outer plexiform layer (OPL) (Fig. 2 B). ApoER2 was not detected in ApoER2 KOs (Fig. $2 D)$. Glycine transporter 1 (GlyT-1) is expressed by all glycinergic amacrine cells, including A-II amacrine cells (Rice and Curran, 2000). To establish the identity of the major ApoER2-expressing cell types, we colabeled P7 wild-type and ApoER2 KO retinas for ApoER2 and GlyT-1 (Fig. $2 H-J$ ). Expression of ApoER2 was detected in A-II amacrine cells expressing GlyT-1 (Fig. 2J, arrow). Both GlyT-1-positive cells in full view had an intense band of ApoER2 expression. While not all A-II amacrine cells were found to have this intense perisomatic localization of ApoER2, we did observe less intense ApoER2-positive puncta in all A-II amacrine cells visualized (data not shown). The enriched expression of ApoER2 in substratum $1(\mathrm{~s} 1)-\mathrm{s} 2$ appeared to originate from another amacrine or bipolar cell type that expressed ApoER2 but not GlyT-1 (Fig. $2 \mathrm{H}-J$, yellow arrow). ApoER2 KOs failed to show specific staining for ApoER2 (Fig. $2 K-M$ ). We determined that all cells expressing GlyT-1 were A-II amacrine cells, based on Dab1/GlyT-1 colabeling (Fig. $2 \mathrm{~N}-\mathrm{P}$ ). Together, these data suggest ApoER2 is predominantly expressed by both A-II amacrine cells and a nonglycinergic amacrine or bipolar cell type in the developing retina. 

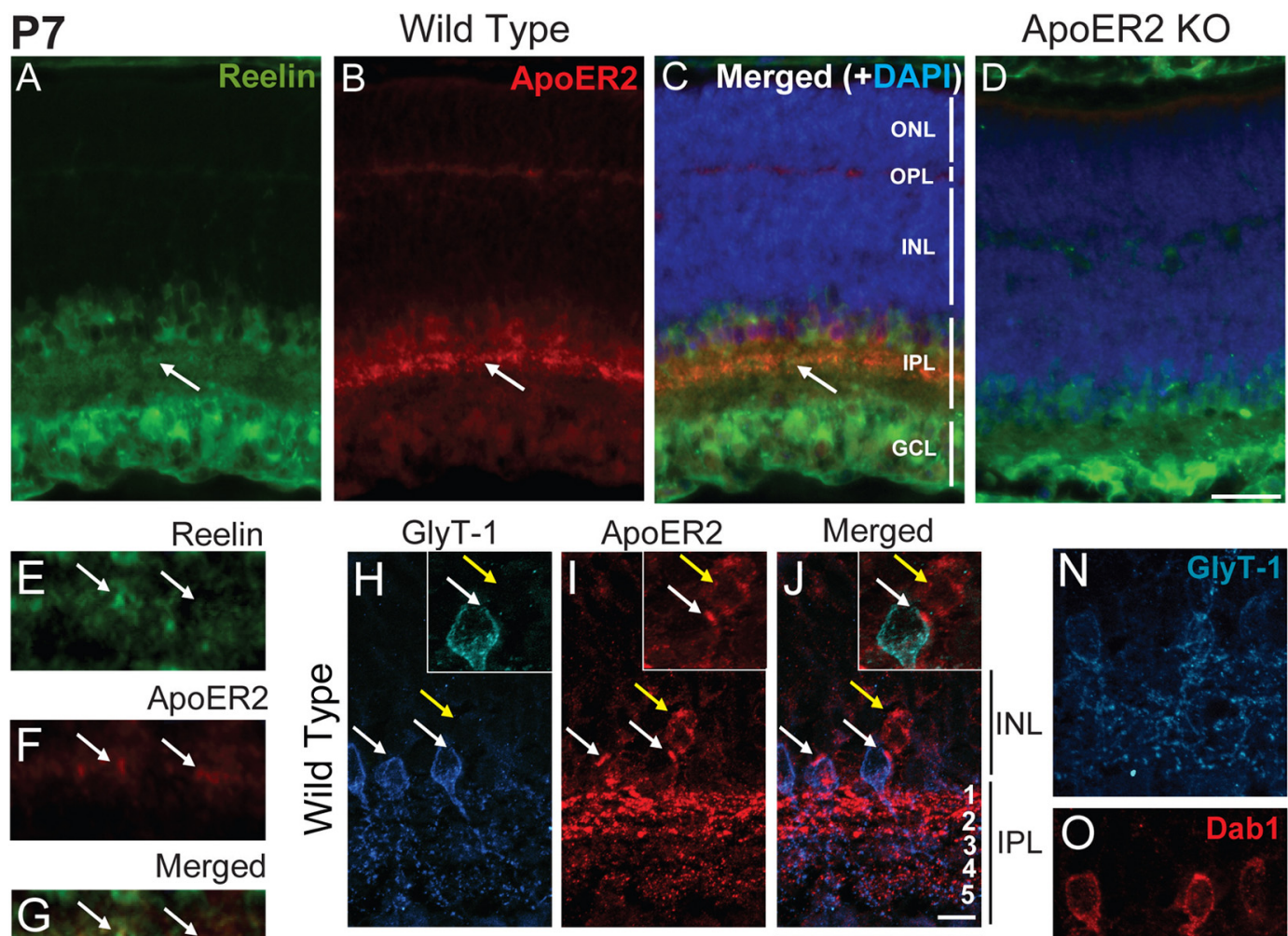

Merged
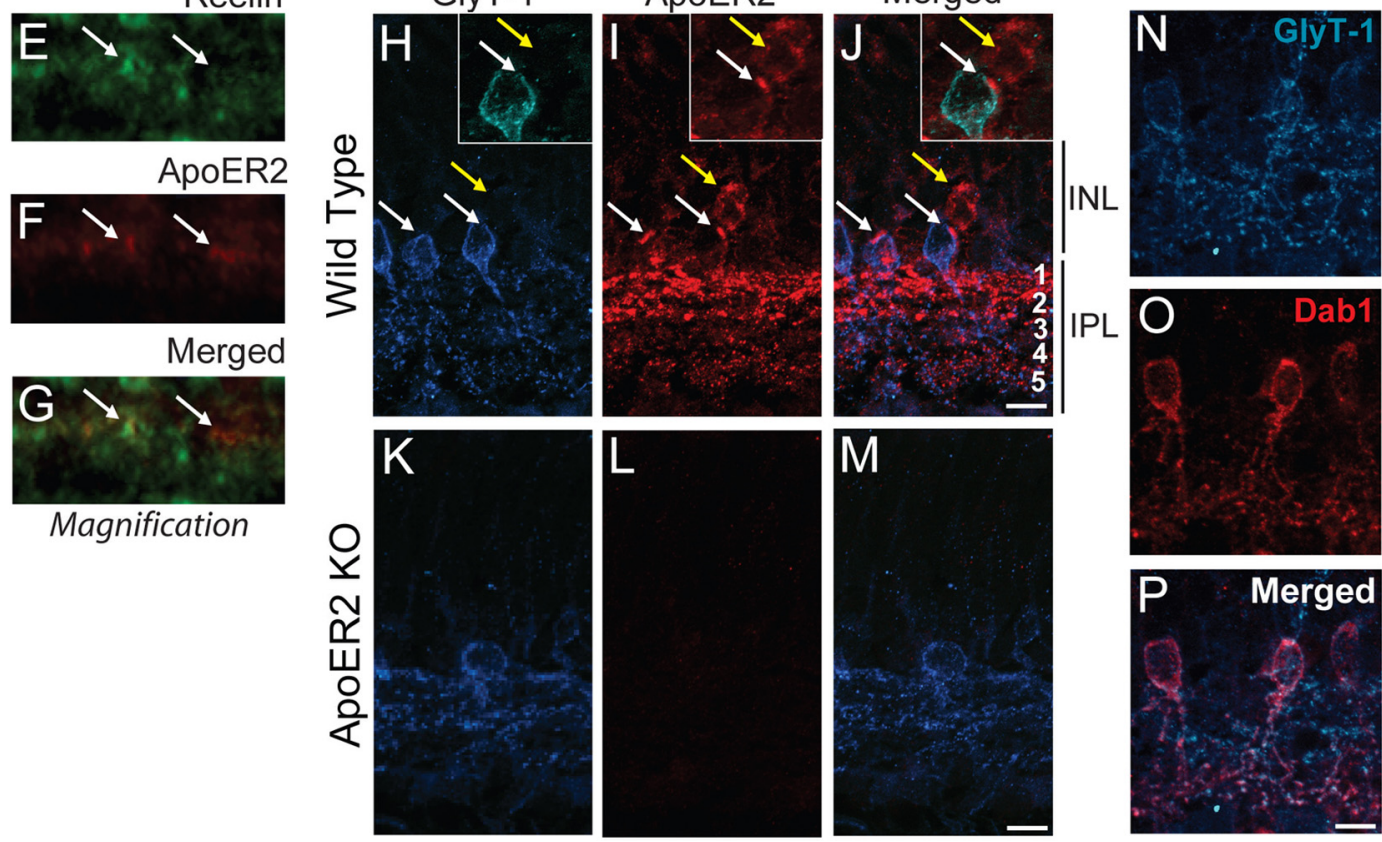

Magnification

Figure 2. Localization of ApoER2 in the retina at P7. $\boldsymbol{A}-\boldsymbol{D}, \mathrm{P7}$ retinas from wild-type ( $\boldsymbol{A}-\boldsymbol{C})$ and $A p 0 E R 2 \mathrm{KO}$ mice (D) were immunostained for ApoER2 (red) and Reelin (green). They were also colabeled with DAPI (blue) to indicate nuclear layers. Reelin was highly expressed by bipolar, amacrine, and ganglion cells and enriched in the IPL. ApoER2 was prominently expressed by a subset of cells residing within the INL and in their projections in the IPL. ApoER2 was also expressed in the OPL and faintly throughout the INL. ApoER2 and Reelin colocalized in the IPL (A-C, arrows). D, Similar expression of Reelin was detected in ApoER2 KOs, but ApoER2 could not be detected. E-G, A $10 \mu \mathrm{m}$ segment of the ApoER2/Reelin-positive stratum identified in A-C by arrows is magnified. Two colocalizing clusters of synapses are indicated with arrows. $\boldsymbol{H}-\mathbf{J}$, ApoER2 and GlyT-1 colocalized in cells alongside the IPL (white arrows), while ApoER2 was also detected in GlyT-1-negative cells (yellow arrows). In the IPL, ApoER2 was most abundant in s1-s2 (OFF strata), where it also partially colocalized with GlyT-1. ApoER2 was also sparsely detected and colocalized with GlyT-1 in s3- 55 (ON strata). $\boldsymbol{K}-\boldsymbol{M}, A p o E R 2 \mathrm{KO}$ s had altered distribution of GlyT-1 and no specific ApoER2 signal. The identity of A-Il amacrine cells was confirmed by colocalization of GlyT-1 (blue) and Dab1 (red). Scale bars: $\boldsymbol{D}$ (for $\boldsymbol{A}-\boldsymbol{D}) 30 \mu \mathrm{m} ; \boldsymbol{J}($ for $\boldsymbol{H}-\boldsymbol{J}), \boldsymbol{M}$ (for $\boldsymbol{K}-\boldsymbol{M}$ ), $\boldsymbol{P}$ (for $\boldsymbol{N}-\boldsymbol{P}) 5 \mu \mathrm{m}$.

\section{ApoER2 expression in the adult retina}

We next determined the localization of ApoER2 in the adult retina, where ApoER2 protein expression levels are considerably lower. GlyT-1, ApoER2, and Dab1 were colabeled to determine the cellular origin of adult ApoER2 expression. This staining employed sequential same-species antibody labeling optimized to prevent cross-labeling (described in detail in Materials and Methods). ApoER2 knock-outs were used to verify antibody specificity. GlyT-1 and Dab1 colabeled A-II amacrine cells that extended bistratified dendrites into the IPL, particularly in s1-s2 and s5 (Fig. A,C). GlyT-1 also recognized additional Dab1-negative (non-A-II) glycinergic amacrine cells and their dendrites in the IPL (Fig. 3D). ApoER2 expression overlapped with Dab1/GlyT-1 and was detected predominantly in $\mathrm{s} 1-\mathrm{s} 2$ and more sparsely throughout s3-s5. Also, ApoER2 was found in the OPL and throughout the INL, but the cellular origin was difficult to deter- mine (Fig. 3B). Low nonspecific staining was observed in ApoER2 KOs (Fig. $3 E-H$ ), confirming the specificity of the antibody. Colocalization between ApoER2 and Dab1 was determined using the Axiovision colocalization module, and scatter plots were generated (Fig. 3I,J). Specific colocalization was gated by using the highest threshold in which colocalization was not seen in the INL and IPL of ApoER2 knock-outs. ApoER2 and Dab1 colocalized significantly throughout the INL and IPL of wild-type retinas (Fig. 3I, red box; Mander's coefficient, $>0.96$ ) but not in ApoER2 KOs. These results indicate that ApoER2 and its adaptor protein Dab1 are coexpressed by A-II amacrine cells of the adult retina.

\section{ApoER2 is required for rod bipolar and A-II amacrine morphogenesis}

Colocalization of Dab1 and ApoER2 in A-II amacrine cells in both the developing and adult retina suggests that ApoER2 might 


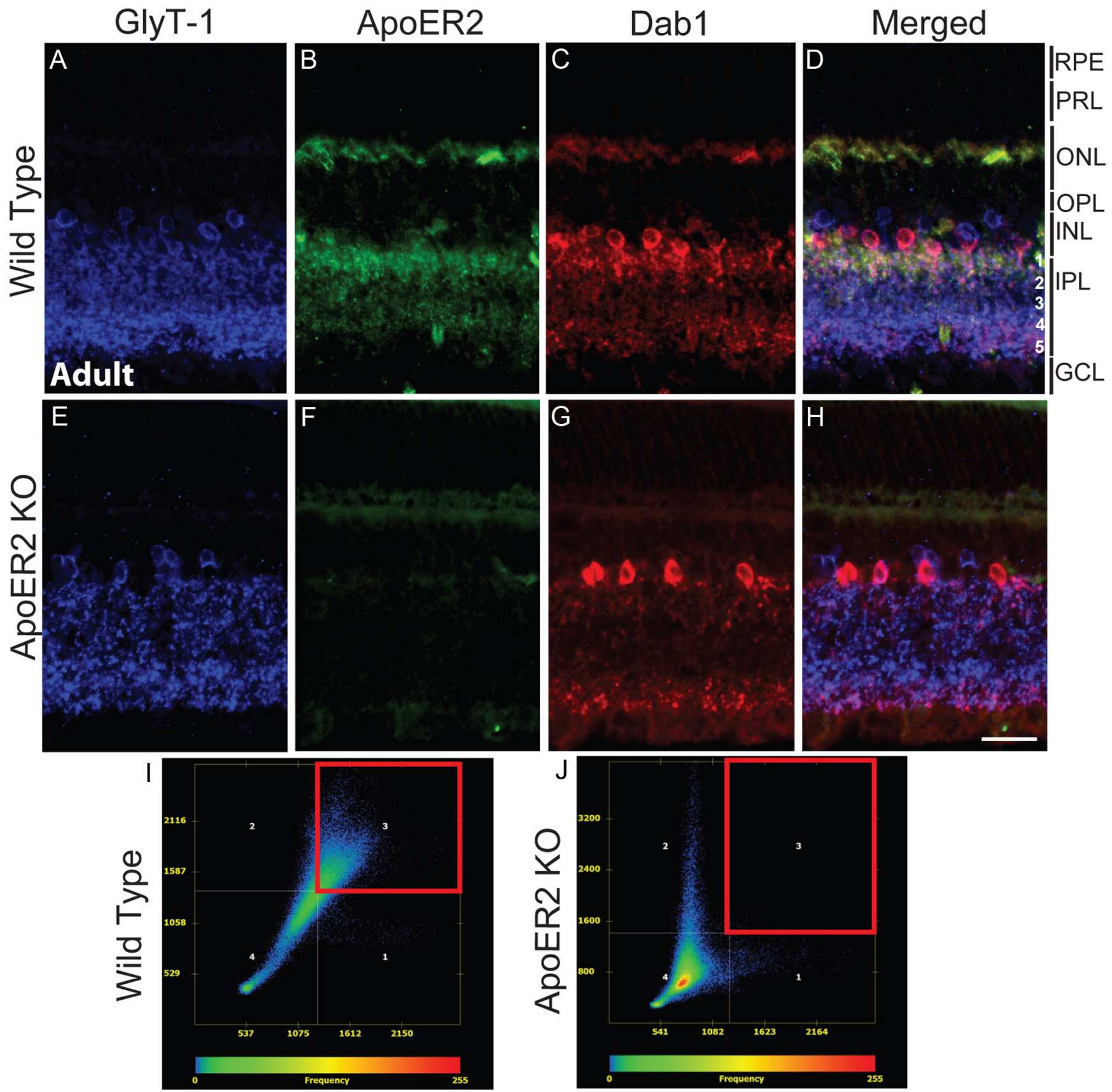

Figure 3. Expression of ApoER2 in the mature retina. $\boldsymbol{A}-\boldsymbol{H}$, The expression of GlyT-1 (blue), ApoER2 (green), and Dab1 (red) was determined in the mature wild-type (A-D) and ApoER2 KO (E-H) retina. In both, glycinergic amacrine cells formed two strata of synapses in the IPL, which comprise $\$ 1-s 2$ (OFF sublamina) and $s 3-s 5$ (ON sublamina) (A,E). ApoER2 was expressed predominantly in s1-s2, but could also be detected in $s 3-s 5$, the INL, and OPL $(\boldsymbol{B})$. ApoER2 could not be detected in KOs $(\boldsymbol{F})$. Some tissue autofluorescence is evident, particularly in photoreceptor segments. $\boldsymbol{C}$, $\boldsymbol{G}$, Dab1 was expressed by A-II amacrine cells in both wild-type and ApoER2 KO retinas, though A-ll amacrine morphology was perturbed in KO retinas. Colocalization between Dab1, ApoER2, and GlyT-1 was evident in wild-type retinas $(\boldsymbol{D})$ and analyzed using the Axiovision colocalization software module. $\boldsymbol{I}, \boldsymbol{J}$, Colocalization scatter plots were generated with the threshold established by eliminating background colocalization in ApoER2 KOs. Only the INL and IPL were included for analysis. Colocalized pixels gated in the red box reveal significant colocalization between ApoER2 and Dab1 in wild-type retinas (I) but not in ApoER2 KOs (J). Scale bar: $\boldsymbol{H}$ (for $\boldsymbol{A}-\boldsymbol{H}$ ), $30 \mu \mathrm{m}$.

transduce the Reelin signal during rod bipolar morphogenesis. To determine whether ApoER2 deficiency affects A-II amacrine or rod bipolar development, we performed double labeling of Dab1 and PKC $\alpha$, which is highly expressed by rod bipolar cells (Haverkamp and Wassle, 2000). We found that rod bipolar morphogenesis requires signaling of Reelin through ApoER2, as mice deficient in ApoER2 (Fig. 4D-F) develop similar rod bipolar morphogenic defects as those seen in Reln mutant mice (Fig. $4 P-R)$. In adult wild-type retinas, A-II amacrine cells formed bistratified dendrites comprising a dense network of appendages in s1-s2. Distal dendrites were localized to s5 where they form synapses with PKC $\alpha$-expressing rod bipolar axon termini (Fig. $4 A-C)$. Loss of ApoER2 resulted in the failure of a subpopulation of rod bipolar cells to properly extend axons into the IPL. Instead, ectopic axons typically formed multiple swollen, terminicontaining varicosities along the IPL, often associated with A-II amacrine dendrites (Fig. 4D-F, arrow). A pronounced reduction in A-II amacrine dendrites in s5 was also evident in ApoER2 KOs. 

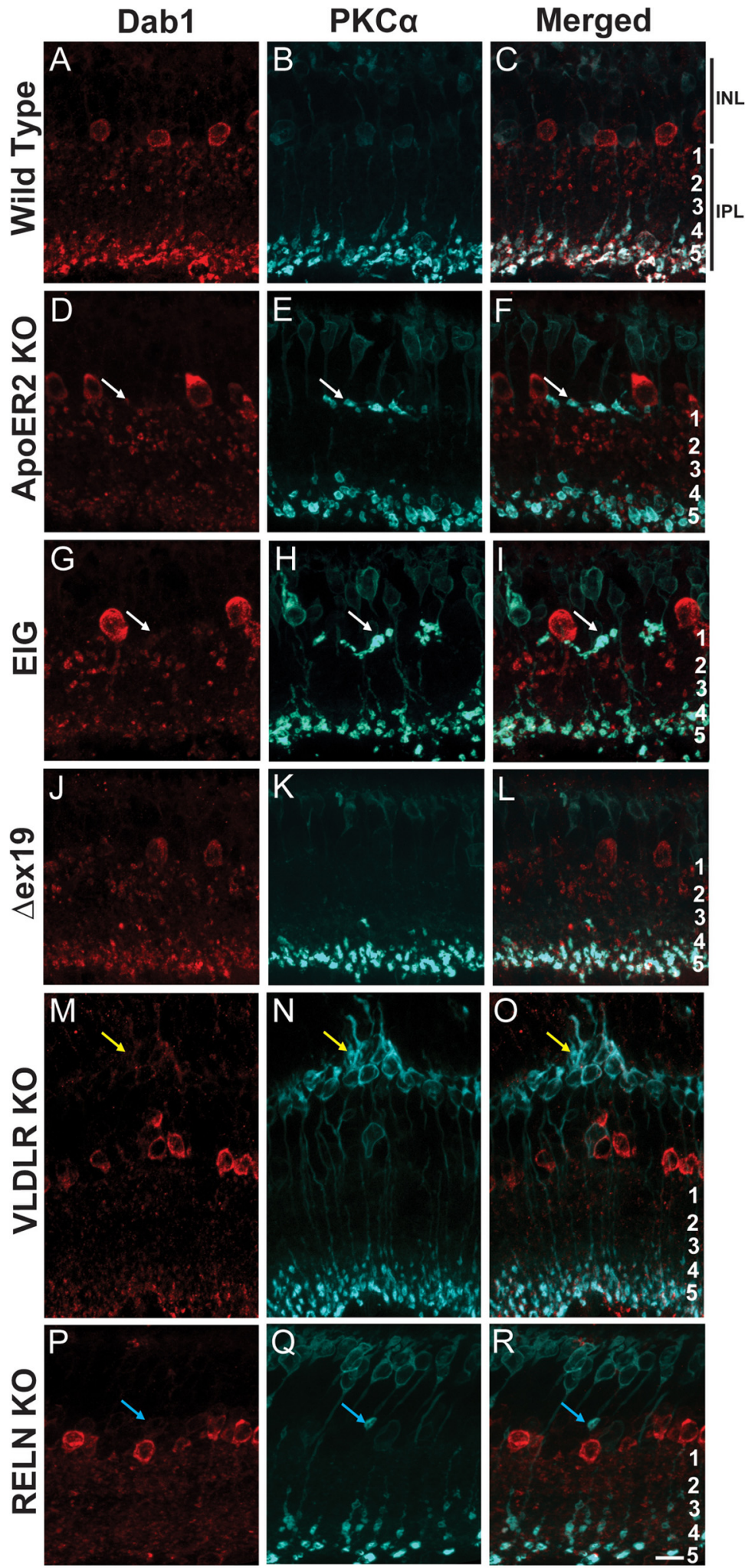

Figure 4. ApoER2 is important for rod bipolar and A-II amacrine morphogenesis. A-Il amacrine and rod bipolar morphology was determined using Dab1 (red) and PKC $\alpha$ (blue) colabeling, respectively. $\boldsymbol{A}-\boldsymbol{C}$, Wild-type retinas had a typical distribution of ON rod bipolar axons in 55 and cell bodies present in the outermost portion of the INL. A-II amacrine dendrites were predominantly localized to s1-s2 and s5. D-F, A subpopulation of rod bipolar axons failed to penetrate the IPL in ApoER2 K0 mice and formed multiple terminals along the border of the IPL and INL. Ectopic terminals were often associated with A-Il amacrine dendrites (white arrows), which were also notably less abundant in s5. G-I, Similarly, ApoER2-EIG mice had rod bipolar axons that failed to penetrate the IPL and had reduced A-II amacrine dendrites in 55 . J-L, ApoER2 $\Delta$ ex 19 mice had normal rod bipolar and A-II amacrine morphology. M-0, Although rod bipolar axons terminated properly in VLDLR KOs, structural remodeling of their dendrites occurred around sites of neovascularization (yellow arrows). A-Il amacrine dendrites were also less distinct in the IPL, and
We then evaluated the ApoER2-EIG mice, which are knock-in mice that express ApoER2 with a mutated NPxY motif (amino acid NFDNPVY changed to EIGNPVY). The NPxY mutation prevents binding of Dab1 to ApoER2 and blocks transmission of the Reelin signal (Beffert et al., 2006b). These mice had rod bipolar axon termination defects and reduced A-II amacrine dendritic arborization (Fig. 4G-I) similar to ApoER2 KOs. In contrast, knock-in mice exclusively expressing ApoER2 without the alternatively spliced exon 19 (ApoER2Aex19) showed no morphogenic defects in either cell type (Fig, $4 J-L$ ).

As Reelin requires both ApoER2 and VLDLR to signal during embryonic corticogenesis (Trommsdorff et al., 1999), we determined whether VLDLR is involved in the development of normal rod bipolar axons or A-II amacrine dendrites. Mice deficient in $V L D L R$ did not display defects in rod bipolar morphogenesis. However, extensive rod bipolar remodeling was observed around sites of neovascularization (Fig. $4 M-O$, yellow arrow). Similar to ApoER2 $\mathrm{KO}$ and ApoER2-EIG mutants, A-II amacrine dendrites in s5 were notably less distinct. A-II amacrine dendrites were also found to remodel around sites of neovascularization (Fig. $4 M$ ). In the present study, the VLDLR KO was the only strain of mice we analyzed that developed neovascularization. Since reeler mice do not develop a vascular phenotype, these findings together suggest that occurrence of neovascularization is independent of Reelin signaling.

Deficiency of Reelin resulted in rod bipolar and A-II amacrine morphogenic defects (Fig. 4P-R), which resembled published findings (Rice et al., 2001). Unlike ApoER2 KO and ApoER2-EIG retinas, ectopic rod bipolar axons contained only a single swollen axonal varicosity (Fig. 4Q, blue arrow). Colabeling of PKC $\alpha$ and ApoER2 in Reln mutant mice revealed that ectopic rod bipolar axons always terminated precisely at the border of ApoER2-positive and ApoER2-negative vicinities of the INL/IPL (data not shown). Moreover, A-II amacrine dendrites in s5 were less distinct (Fig. 4P) than in wild-type controls, and A-II ama-

remodeling occurred around sites of neovascularization. $\boldsymbol{P}-\boldsymbol{R}$, Failure of rod bipolar axons to penetrate the IPL is evident in Reln mutant mice (blue arrows), but axons did not form multiple terminals. Similar to VLDLR KOS, A-II amacrine dendrites throughout the IPL were less distinct. Scale bar: $\boldsymbol{R}$ (for $\boldsymbol{A}-\boldsymbol{R}), 10 \mu \mathrm{m}$. 

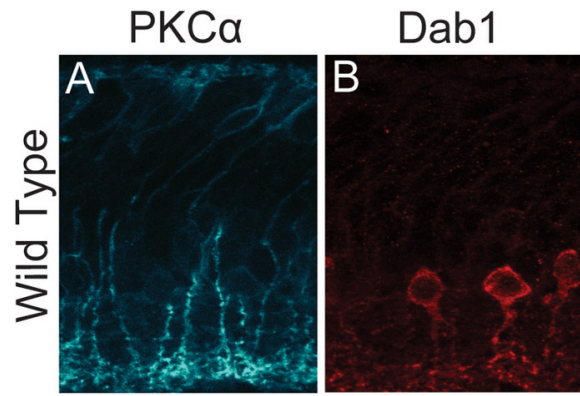

\section{Merged}
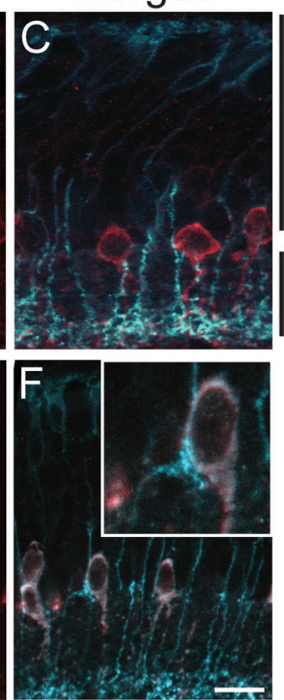

Dab1
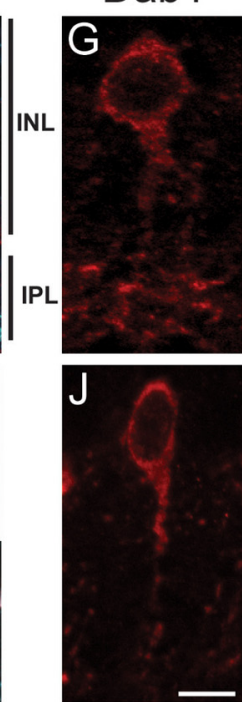

GlyT-1
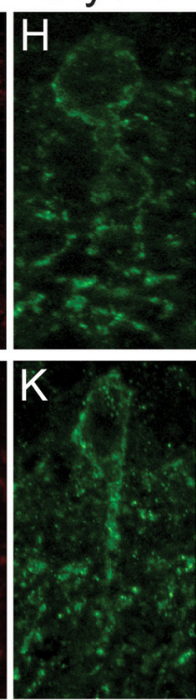

Merged
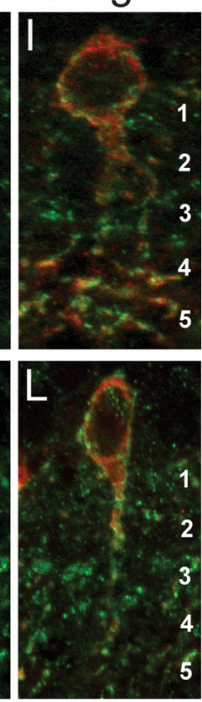

Figure 5. A-ll amacrine morphology is perturbed in ApoER2 KOs at P7. Dab1 (red) and PKC $\alpha$ (blue) colabeling was performed on wild-type and ApoER2 K0 retinas from P7.A-C, Rod bipolar axons extended into the IPL of wild-type retinas where they branched and started to form swollen varicosities in close association with $A$-Il amacrine dendrites. $\boldsymbol{D}, \boldsymbol{E}$, The density of branched rod bipolar axons is reduced in $A$ poER2 KOs, paralleled by severely reduced dendritic arborization of A-II amacrine cells. PKC $\alpha$ was highly expressed by A-II amacrine cells in ApoER2 KO but not wild-type retinas. Upon closer magnification of $\boldsymbol{F}$, a late developing rod bipolar axon can be seen in tight association with A-Il amacrine soma. G- $\mathbf{L}$, GlyT-1 was also used as a colabel (green) to visualize changes in A-II amacrine morphology. G-H, An A-II amacrine cell from C was magnified, revealing a dominant layer of dendritic appendages in s 5 of a wild-type retina. GlyT-1 not colocalized with Dab1 likely represents synapses belonging to other glycinergic amacrine cells. $\boldsymbol{J}-\boldsymbol{L}$, In contrast, the A-II amacrine cell asterisked in $\boldsymbol{F}$ had a significant reduction in Dab1/GlyT-1-positive dendrites in s5. Scale bars: $\boldsymbol{F}$ (for $\boldsymbol{A}-\boldsymbol{F}$ ), $10 \mu \mathrm{m} ; \boldsymbol{J}($ for $\mathbf{G}-\boldsymbol{L}), 5 \mu \mathrm{m}$.

crine cells were often found to extend processes into the OPL. Collectively, these data support a role for the signaling of Reelin through ApoER2 in the development of rod bipolar axons and establishment of proper A-II amacrine morphology.

\section{Alterations in A-II amacrine morphology in ApoER2 KO at P7}

The inability of only a subpopulation of an otherwise functionally homogenous population of rod bipolar cells to terminate appropriately in the IPL of ApoER2 KO mice suggests that this developmental effect may be secondary to developmental perturbation of their postsynaptic partners (i.e., A-II amacrine cells). We evaluated A-II amacrine morphology in wild-type and ApoER2 KO mice at P7. PKC $\alpha$-labeled rod bipolar axons extended into the IPL of wild-type retinas, where they branched and started to generate swollen varicosities in close association with A-II amacrine dendrites in s5 (Fig. $5 A-C)$. In ApoER2 KOs the density of branched rod bipolar axons was reduced and mirrored by profound reductions in the dendritic arborization of A-II amacrine cells in s5 (Fig. 5D-F). Interestingly, PKC $\alpha$ was highly expressed by A-II amacrine cells in ApoER2 KO but not wild-type retinas. Upon closer magnification, several potentially ectopic rod bipolar axons were found terminated in tight association with A-II amacrine somas in ApoER2 KOs (Fig. 5F, inset). The same colabeling included GlyT-1 as another A-II amacrine marker to ensure that observed changes were not simply due to altered Dab1 expression and/or trafficking in the absence of one of its major receptors. Both GlyT-1 and Dab1 were dramatically reduced in 55 of ApoER2 KOs (Fig. 5J-L) relative to wild-type controls (Fig. $5 G-I)$, suggesting impaired A-II amacrine morphology at a stage of retinal development when rod bipolar cells are completing extension of their axons and developing appropriate synapses.

\section{Impairment of A-II amacrine morphology in adult ApoER2 KO}

We next determined whether A-II amacrine cells at P7 had delayed dendritic maturation that recovered with age or whether their morphology was also impaired in the adult retina at both 3-5 and 10-14 months of age. Typical bistratified A-II amacrine cells were found in both 3- to 5-month-old and 10- to 14-monthold wild-type retinas (Fig. $6 A, C$ ). However, A-II amacrine dendrites were reduced in s5 of 3 - to 5 -month-old (Fig. $6 B$ ) and in both s1-s2 and s5 of 10- to 14-month-old ApoER2 KO retinas (Fig. 6D). These data indicate that A-II amacrine morphology is perturbed in ApoER2 KOs both in development and in the aging adult retina, raising the possibility that physiological differences in retinal function may also be present.

\section{ApoER2 deficiency results in altered synaptic connectivity}

We determined to what extent loss of ApoER2 would resemble previous electroretinography findings with Reelin and Dabl mutant mice and how these changes differed with age. In addition, we tested VLDLR KO mice to determine the contribution of this receptor to Reelin signaling during the establishment of normal synaptic connectivity. ApoER2-EIG knock-in mice were also used to determine Dab1-dependent and Dab1-independent contributions of ApoER2 to retinal function. Mice were tested at either young age (YA; 3-5 months old) or middle age (MA; 10-14 months old). Wild-type mice (YA, $n=7$; MA, $n=8$ ) were compared to ApoER2 KO (YA, $n=8$; MA, $n=7$ ), ApoER2-EIG (YA, $n=4$; MA, $n=9)$, and VLDLR KO (YA, $n=7$; MA, $n=15$ ) mice using a range of rod- and cone-isolated full-field electroretinogram parameters.

The rod-isolated b-wave was reduced in ApoER2 KOs (YA, MA; both $p<0.01$ ), ApoER2-EIG mice (YA, MA; both $p<0.01$ ), and VLDLR KOs (MA only, $p<0.01$ ) (Fig. 7B). An agedependent reduction in b-wave was seen in both ApoER2 KOs and VLDLR KOs ( $p<0.01$ and $p<0.001$, respectively), but not ApoER2-EIG KO mice $(p>0.05)$. The age-dependent impairment of the rod b-wave in VLDLR KOs is consistent with the progressive retinal degeneration observed in these mice. In addition, we found significant delays in the timing of the rod-isolated b-wave in ApoER2-EIG (MA, $p<0.01$ ) and VLDLR KO mice 


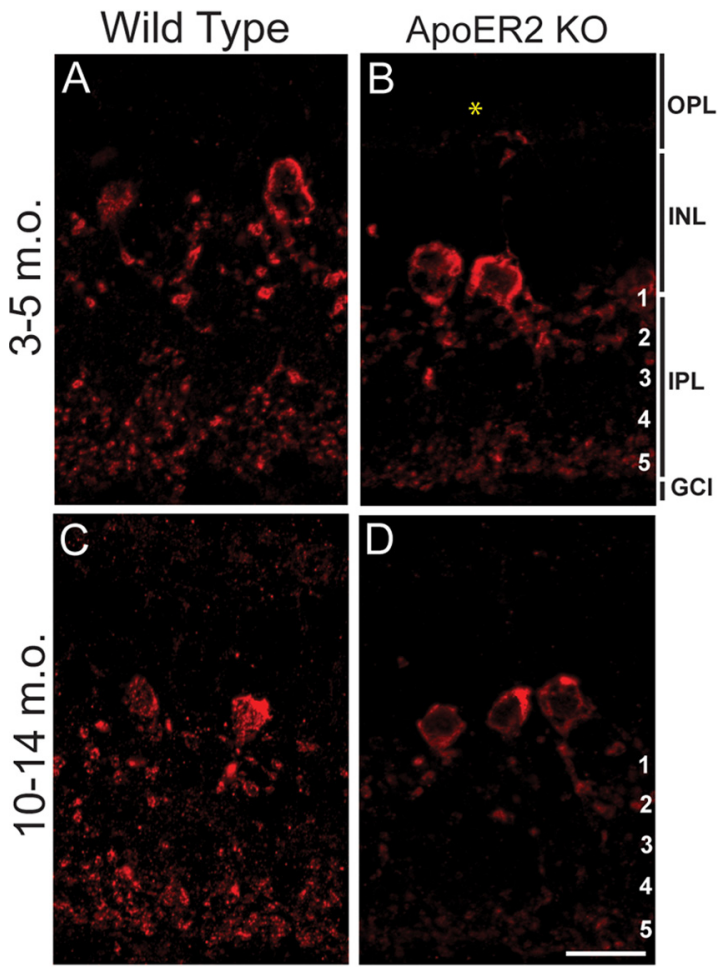

Figure 6. Loss of ApoER2 is associated with altered A-II amacrine morphology in the aging retina. Dab1 (red) was labeled to visualize changes in A-II amacrine morphology in 3- to 5-month-old (m.0.) and 10- to 14-month-old wild-type and ApoER2 KO mice. A, C, Typical bistratified A-II amacrine morphology was observed in both 3-5 and 10-14 m.o. wild-type mice. $\boldsymbol{B}, \boldsymbol{D}, \mathrm{A}$ prominent reduction in $\mathrm{A}-\mathrm{Il}$ amacrine dendrites was observed in 55 of both $3-5$ and $10-14$ m.o. ApoER2 KO retinas. The asterisked ectopic A-II amacrine dendrite in the OPL was observed frequently in ApoER2 $\mathrm{KO}$ s of all ages. A-II amacrine appendages in $\mathrm{s1-s2}$ and distal dendrites in 55 were further reduced in 10-to 14-month-old than 3- to 5-month-old ApoER2 KO. Scale bar: $\boldsymbol{D}$ (for $\boldsymbol{A}-\boldsymbol{D}), 10 \mu \mathrm{m}$.

(YA, $p<0.0001$; MA, $p<0.005$ ) (Fig. 7A). The scotopically elicited combined ERG revealed similar differences (Fig. $7 A$ ), reinforcing the finding of impaired rod transmission in these mice.

We did not detect significant changes in summed OPs in ApoER2 KOs $(p>0.05)$, but found reduced summed OP amplitude in ApoER2-EIG (YA, $p<0.05$; MA, $p<0.01$ ) and VLDLR KOs (YA, MA; both $p<0.01$ ) (Fig. 7C). There was also an agedependent decrease in OP amplitude in VLDLR KOs $(p<0.01)$.

A photopic stimulus used to elicit transmission through the cone pathway revealed only a slight increase in amplitude in $V L D L R$ KOs (YA, $p<0.05$ ) (Fig. 8A). However, the cone-isolate response implicit time was modestly decreased in ApoER2-EIG mice (YA, $p<0.05$ ) and increased in VLDLR KO mice (MA, $p<$ 0.05) (Fig. 8A). Another measure of cone function, the $30 \mathrm{~Hz}$ CFR, revealed several important differences. First, the CFR amplitude was impaired in ApoER2 KO mice (MA, $p<0.001$ ) and $V L D L R$ KO mice (MA, $p<0.01$ ) (Fig. $8 B$ ). Second, these effects were due to an age-dependent reduction in CFR amplitude (both $p<0.01$ ); however, there were no changes in CFR implicit time (Fig. $8 \mathrm{~B}$ ). These findings indicate that loss of signaling through either ApoER2 or VLDLR results in significant age-dependent changes in retinal synaptic connectivity.

\section{Fundoscopic analysis of ApoER2 KO mice}

$V L D L R$ KOs display vascular leakage by 3 weeks of age and typical colloidal neovascularization fluorescein angiographs by 6 weeks
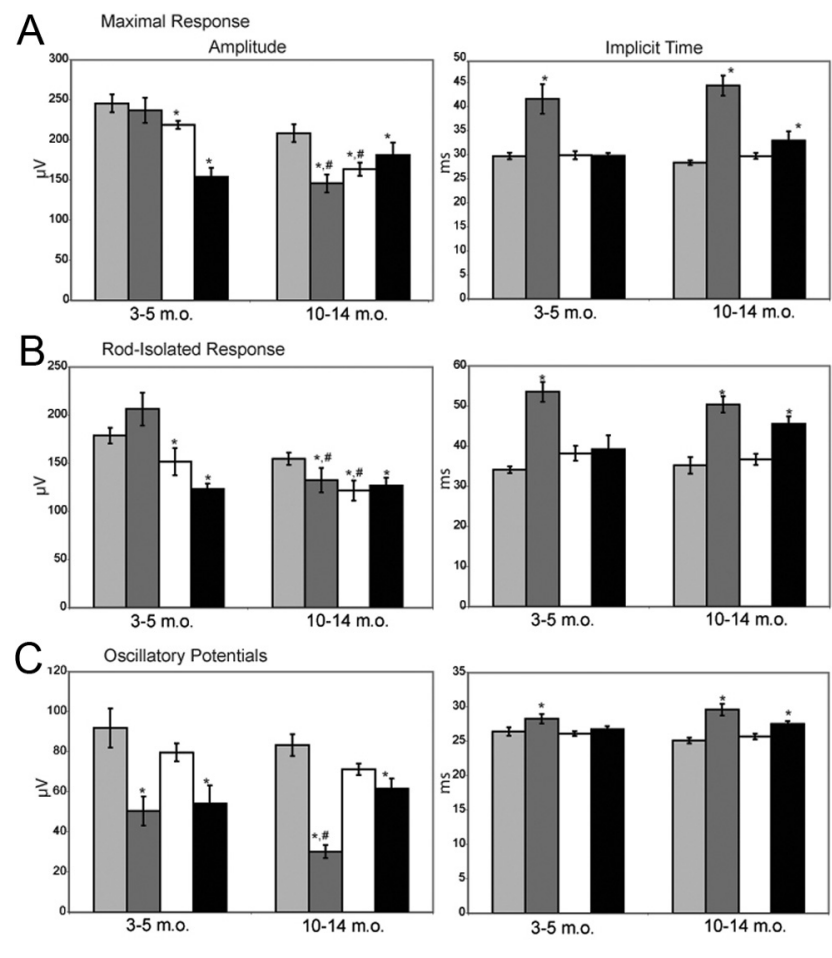

$\square W T$

\section{$\square$ VLDLR KO $\square$ ApoER2 KO ApoER2-EIG}

Figure 7. ApoER2 and VLDLR differentially affect the establishment and maintenance of the rod pathway synaptic connectivity. YA [3-5 months old (m.0.)] and MA (10-14 m.0.) mice were tested. $\boldsymbol{A}$, Standard combined responses (maximal response) revealed impaired amplitude (in microvolts) in ApoER2-EIG (YA, $p<0.001$; MA, $p<0.05$ ), ApoER2 KO (YA, MA, $p<$ 0.001 ), and VLDLR KO (MA, $p<0.001$ ) mice. There were significant age-dependent reductions of combined ERG amplitude in both VLDLR and ApoER2 KO mice (both $p<0.0001$ ). A delay in standard combined response intervals (implicit time, in milliseconds) was found in ApoER2-EIG (MA, $p<0.01$ ) and VLDLR KO mice (YA, $p<0.01$; MA, $p<0.005$ ). $\boldsymbol{B}$, Rod-isolated responses were reduced in ApoER2 KO (YA, MA, $p<0.01$ ), VLDLRKO (MA, $p<0.01$ ), and ApoER2-EIG mice $(\mathrm{YA}, \mathrm{MA}, p<0.01)$. An age-dependent reduction in amplitude was seen in both $A p 0 E R 2 \mathrm{KO}$ and $V L D L R K 0$ mice ( $p<0.01$ and $p<0.001$, respectively). The rod-isolated response interval was delayed in ApoER2-EIG (MA, $p<0.01$ ) and VLDLR KO mice (YA, $p<0.0001 ; M A, p<0.005)$. C, The amplitude of summed OPs were markedly reduced in VLDLR KO (YA, MA, $p<0.01$ ) and ApoER2-EIG (YA, $p<0.05$; MA, $p<0.01$ ). An age-dependent decrease in OPs was seen only with VLDLRKO $(p<0.01)$. The response intervals for oscillatory potentials elicited were delayed in both VLDLR KO (MA, $p<0.0001$ ) and ApoER2-EIG mice (MA, $p<0.001)$. Error bars indicate SEM. ${ }^{*} p<0.05$ (significance when compared to within age-group wild-type controls indicated by two-tailed Student's $t$ test); ${ }^{*} p<0.05$ (significance when MA compared to same YA group indicated by two-tailed Student's $t$ test).

of age (Heckenlively et al., 2003; Hu et al., 2008). To determine whether loss of ApoER2 resulted in gross, age-related changes in eye morphology, we performed fundus examination using fundus photography and fluorescein angiography. We found that at $10-14$ months of age, ApoER2 KO mice $(n=3)$ had areas of focal vascular leakage that were sometimes accompanied by depigmented pink spots in the fundus, though the morphological changes were not nearly as severe as those found in VLDLR KOs (Fig. 9). By this age, leakage in the VLDLR KO is still obvious, though not as severe as in the young mouse (data not shown). Furthermore, the pink fundus spots progressed into large, irregular pink areas and dark spots with age similar to published findings (Hu et al., 2008). Unlike VLDLR KOs, which develop robust neovascularization emanating from the OPL within 6 weeks of age, we were unable to detect similar gross histological changes in ApoER2 KO retinas even at old age (data not shown). 
A

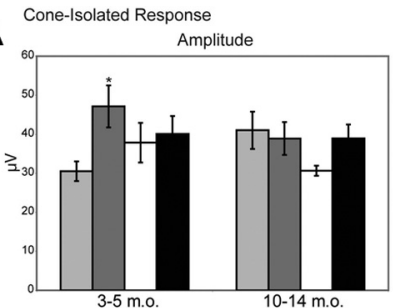

$\mathrm{B}$

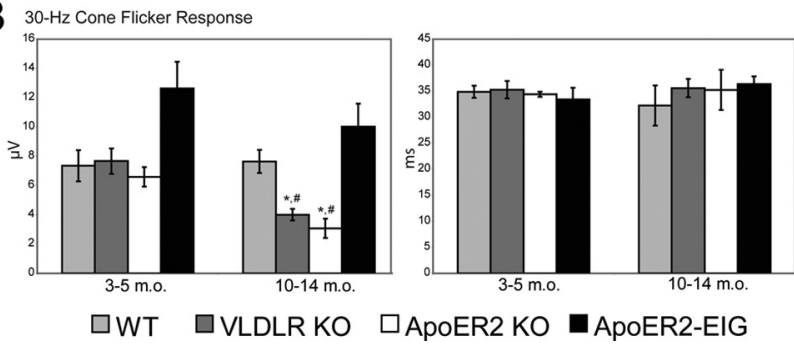

Figure 8. The cone pathway is also affected by $A p 0 E R 2$ and VLDLR deficiency. $\boldsymbol{A}$, The amplitude of synaptic transmission through the cone pathway was enhanced in VLDLR KO (MA, $p<$ $0.05)$. In addition, there were delayed response intervals in VLDLR KO mice (MA, $p<0.05$ ) and a faster interval in ApoER2-EIG mice (YA, $p<0.05)$. B , The $30 \mathrm{~Hz}$ CFR amplitude was impaired in ApoER2 KOs (MA, $p<0.01$ ) and VLDLR KOs (MA, $p<0.01)$, with an age-dependent reduction seen in both ApoER2 and VLDLR KOs ( $p<0.01)$. No significant strain- or age-dependent differences were detected in the response interval of $30 \mathrm{~Hz}$ cone flicker responses $(p>0.05)$. Error bars indicate SEM. * $p<0.05$ (significance when compared to within age-group wild-type controls indicated by two-tailed Student's $t$ test); ${ }^{\#} p<0.05$ (significance when MA compared to same YA group indicated by two-tailed Student's $t$ test).

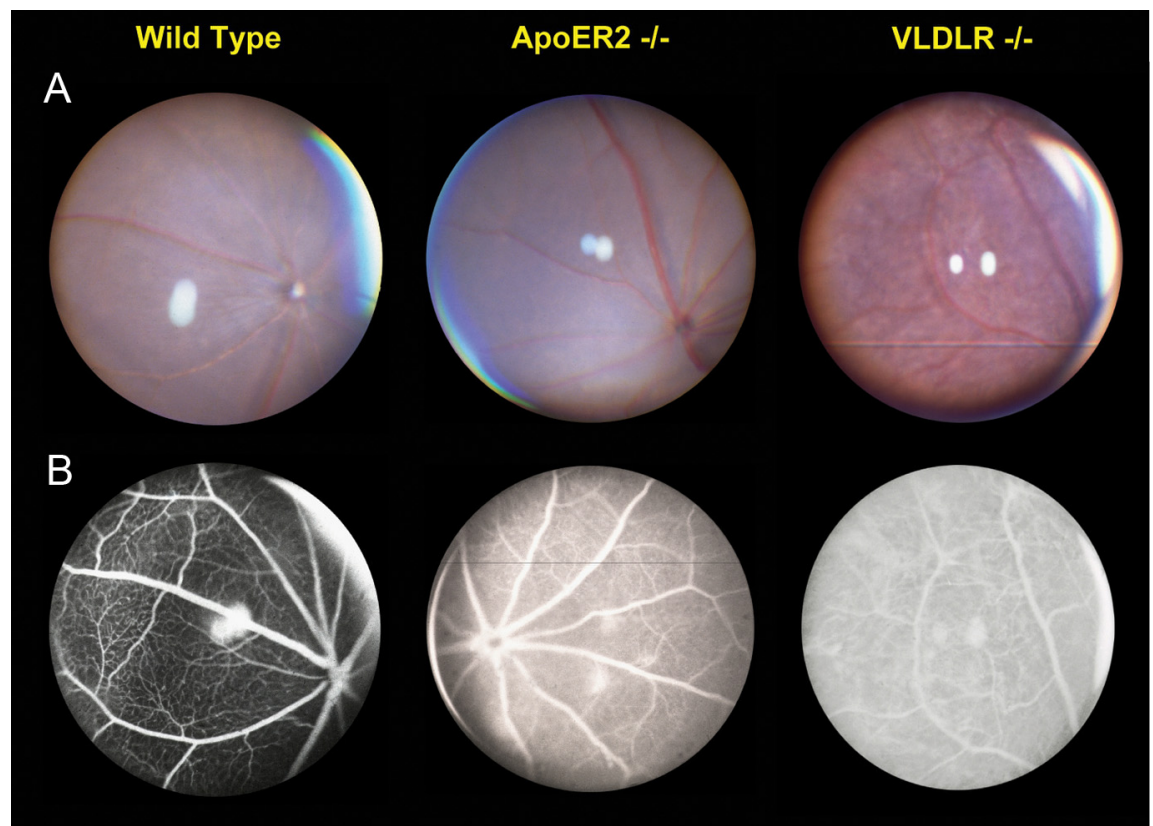

Figure 9. Loss of ApoER2 and VLDLR alters fundus morphology at middle age. $A, V L D L R K 0$ mice displayed reported widespread, patchy, dark deposits across the fundus, while ApoER2 KO mice were similar to wild-type mice. $B, V L D L R$ and ApoER2 KO mice both had capillary leakage indicated by FA; however, the leakage was much more severe in VLDLR KO. Thinning of the capillary layer was also evident in VLDLR KOs.

\section{Discussion}

The events that culminate in the proper synaptic organization of the retina are still poorly understood. Our findings reveal an indispensable role for ApoER2 in the development of the rod bipolar pathway and maintenance of retinal synaptic connectivity. Several ApoER2 isoforms are highly expressed during postnatal retinal development, particularly at a stage when A-II amacrine cells and rod bipolar cells are establishing appropriate synaptic connections. Specifically, ApoER2 expression is highest in A-II amacrine cells as well as an unidentified nonglycinergic amacrine or bipolar cell type. In the adult retina, ApoER2 is considerably lower but present in both ON and OFF lamina, and is predominantly expressed by A-II amacrine cells. Loss of ApoER2 or impairment of signaling through Dabl results in ectopic rod bipolar morphogenesis, similar to mouse models deficient in Reelin or Dab1 (Rice et al., 2001). However, splicing of ApoER2 at exon 19 and expression of VLDLR are not necessary for this developmental event. Nonetheless, ApoER2, Reelin, and VLDLR are all required for normal development of A-II amacrine dendrites and synaptic connectivity. ApoER2 KO mice have impaired retinal synaptic connectivity, reflected by attenuated rod b-wave amplitude, which partially recapitulates the reeler and scrambler phenotypes (Rice et al., 2001). However, only loss of VLDLR was found to significantly impair oscillatory potential amplitude and delay ERG response intervals, as is found in reeler and scrambler mice, suggesting that ApoER2 and VLDLR are both differentially required for Reelin signaling during retinal development.

The rod bipolar pathway, which conveys signals arising at visual threshold during rod-mediated scotopic vision in mammals (Bloomfield and Dacheux, 2001), transmits information to A-II amacrine cells (Kolb and Famiglietti, 1974). Receiving input from about 20 rod bipolar cells via glutamatergic synapses, A-II amacrine cells then transmit rod information to OFF-cone bipolar cells (via electrical gap junctions) that provide excitatory input to retinal ganglion cells (McGuire et al., 1984). Although a role for A-II amacrine cells in retinal development has not been described previously, restriction of Dab1 and localization of ApoER2 to this cell type during development suggests that altered rod bipolar cell morphology may be secondary to changes in A-II amacrine cell development, a hypothesis that has been suggested previously (Rice and Curran, 2000; Rice et al., 2001). Indeed we present evidence that A-II amacrine dendrite structure is perturbed in ApoER2 KOs as early as P7, which may be responsible for the inability of some rod bipolar axons to terminate appropriately in stratum 5 of the IPL. The failure of rod bipolar axons to find postsynaptic partners may result in retraction of their axons and aberrant termination alongside the IPL/INL border. Our findings that ectopic rod bipolar axons remain in close association with A-II amacrine somas and/or dendrites suggest that Reelin signaling on the surface of A-II amacrine cells may modulate adhesion between elongating rod bipolar axons and A-II amacrine cells, possibly through established effects on the actin cytoskeleton (Chai et al., 2009) or through affecting integrin signaling (Dulabon et al., 2000; Schmid et al., 2005). A role for Reelin signaling in axon path finding has also been demonstrated in the hippocampus, as reeler entorhinal axons have altered morphology and exhibit targeting errors (Del Rio et al., 1997; Borrell et al., 1999). Dscam (encoding down syndrome cell adhesion molecule) KO mice also have impairments in rod bipolar dendrite development and A-II ama- 
crine positioning (Fuerst et al., 2009), further suggesting that development of the two cell types may be interrelated. Ectopic processes are evident as early as $7 \mathrm{~d}$ after birth, after which they become lobulated and associate with A-II amacrine processes. In Reln mutant mice, the ectopic axons fail to form multiple swollen mutant varicosities and are unable to penetrate ApoER2containing strata, indicating that Reelin may act on A-II amacrine through ApoER2 by regulating penetration of rod bipolar axons into the IPL. However, rod bipolar axon lobulation does not appear to require ApoER2. These data provide a potential cellular and molecular mechanism that can be further studied to understand the development of inner retinal circuitry. Until now, this has been hampered by the absence of genetic mouse models with selective defects in retinal synaptic structure.

In the retina, we observed at least five major ApoER2 bands, which could correspond to alternatively spliced (Brandes et al., 2001; Beffert et al., 2005; Hibi et al., 2009), differentially glycosylated (May et al., 2003), and proteolytically processed forms of ApoER2 (May et al., 2003; Hoe and Rebeck, 2005). Although we did not selectively identify the specific ApoER2 isoforms expressed in the retina, we found that they were identical to those expressed in the adult cortex (based on molecular weight) and that all isoforms were significantly reduced in the adult retina compared to the early postnatal retina. In the brain, splicing of ApoER2 at exon 19 is not required for development, but is essential for hippocampal synaptic plasticity (Beffert et al., 2005) and neuronal survival (Beffert et al., 2006a). We found that loss of ApoER2 exon 19 did not result in abnormal rod bipolar morphogenesis or significant alterations in overall synaptic connectivity (data not shown). ApoER2 splicing may be a factor that specifies Reelin function in plastic versus nonplastic circuits; namely, in plastic circuits, Reelin can coordinately regulate aspects of the cell cytoskeleton and adhesion through the conventional, Dab1-dependent/exon 19-independent pathway (Suetsugu et al., 2004; Chai et al., 2009), as well as neurotransmission through exon 19-mediated coupling of the Reelin signaling complex to the NMDA receptor complex (Beffert et al., 2005). NMDARs are indeed expressed by the retina (Zhang and Diamond, 2006) and are important in the rod pathway (Boos et al., 1993; Hartveit and Veruki, 1997), but whether or not the ApoER2 exon 19 splice variant is expressed by and contributes to the functioning of the retina remains a topic of ongoing investigation.

The rod b-wave of the full-field ERG originates from the combined activity of depolarizing rod bipolar cells and bipolar celldependent potassium channel currents affecting Müller glia (Heynen and van Norren, 1985a,b). Observed reductions in the rod b-wave in ApoER2 $\mathrm{KO}$ and ApoER2-EIG mice are consistent with impaired inner retinal synaptic connectivity and reported b-wave reductions in both reeler and scrambler mice (Rice et al., 2001), albeit less severe. The reduced severity may indicate that combined loss of ApoER2 and VLDLR could be required to fully recapitulate the retinal phenotype of the reeler and scrambler strains. Further impairment of the rod b-wave was observed with age in ApoER2 KOs, suggesting that ApoER2 may play a role in maintenance of retinal synaptic connectivity. Although the changes in the rod pathway were the most profound, there were also age-related impairments of the $30 \mathrm{~Hz}$ cone flicker response in both ApoER2 and VLDLR KO mice. The cone-isolate response was also reduced in ApoER2 KOs at young age, but was normal by middle age. Although we have focused on the morphological development of rod bipolar and A-II amacrine cells, observed changes in cone function could be due to an active role of A-II amacrine cells in photopic vision or due to abnormal synaptic development of cell types that synapse with A-II amacrine cells and also participate in the cone pathway. We postulate that such cell types would be limited to A-II amacrine synaptic partners because of the restricted expression of ApoER2 and Dab1 during development and in the adult. The modest reductions of OP amplitude and delays in timing in ApoER2-EIG mice may stem from secondary effects of adaptor protein availability that could affect the function of VLDLR. Along the same line, normal OP potentials in Apoer2 may reflect functional compensation by other receptors (e.g., VLDLR) that are impaired in the Apoer2-EIG mice.

VLDLR has been the only well-studied lipoprotein receptor in the retina, but the development of neovascularization and retinal degeneration in the VLDLR KO mice has made it difficult to understand the basic functions of this receptor (Heckenlively et al., 2003). Our data suggest that while VLDLR may not play a role in the overall integrity of the rod pathway in young mice that do not yet display any degeneration, its presence is required for normal oscillatory potentials, which are widely believed to represent the activity of secondorder neurons, including amacrine cells (Wachtmeister, 1998). Reduced OPs are also seen in scrambler and reeler mice (Rice et al., 2001), but not in ApoER2 KO mice, further suggesting that VLDLR has a separate Reelin-dependent role in the development of retinal circuitry. Considering the expression of Dab1 by A-II amacrine cells and our findings that VLDLR KOs also had impaired A-II amacrine development, observed impairments in oscillatory potentials may originate from specific impairments in the function of A-II amacrine cells. Moreover, VLDLR KOs had delayed rod b-wave and coneisolated response intervals, which is consistent with findings in scrambler and reeler mice (Rice et al., 2001). We also found that Vldlr KO mice had normal b-wave amplitude at young age, but impairments in the b-wave at old age, suggesting that despite pervasive neovascularization and retinal remodeling, synaptic connectivity in young Vldlr KOs remains largely intact. These data suggest that Reelin acts via both ApoER2 and VLDLR to regulate distinct aspects of retinal synaptic development. Combined, the ApoER2 and VLDLR KOs individually recapitulated all major differences in synaptic connectivity observed previously in reeler and scrambler mice.

The ability to dissociate the roles of both ApoER2 and VLDLR provides an important basis with which we can now study the contribution of human $a p o E$ variants to retinal pathology. Indeed, apoE isoforms have been demonstrated previously to differentially affect the surface availability of ApoER2 in neurons and thereby alter Reelin-dependent synaptic plasticity (Chen et al., 2010). Whether or not apoE isoforms exert similar effects on lipoprotein receptors expressed by the retina remains to be addressed. Although more subtle than the neovascular phenotype of VLDLR KOs, ApoER2 KOs have age-related changes in synaptic morphology as well as some vascular leakage. Further disruption of A-II amacrine morphology in 10- to 14-month-old ApoER2 KOs and disruption of both rod and cone synaptic transmission indicate that ApoER2 may also have a role in maintenance of synaptic connectivity in the rod bipolar pathway. A similar proposal has been made recently for Reelin signaling in maintaining cortical architecture in the adult (Frotscher, 2010).

In summary, the findings presented here provide strong genetic evidence that ApoER2 is required for Reelin-dependent development of both rod bipolar and A-II amacrine cells. We have also identified unique roles for both ApoER2 and VLDLR in regulating the development and maintenance of normal retinal synaptic connectivity, which will serve as a basis for the understanding the association of $a p o E$ with retinal pathology and even Alzheimer's disease, as well as the further dissection of the cellular and molecular mechanisms responsible for retinal synaptic development. 


\section{References}

Andrade N, Komnenovic V, Blake SM, Jossin Y, Howell B, Goffinet A, Schneider WJ, Nimpf J (2007) ApoER2/VLDL receptor and Dab1 in the rostral migratory stream function in postnatal neuronal migration independently of Reelin. Proc Natl Acad Sci U S A 104:8508-8513.

Baird PN, Guida E, Chu DT, Vu HT, Guymer RH (2004) The epsilon2 and epsilon 4 alleles of the apolipoprotein gene are associated with age-related macular degeneration. Invest Ophthalmol Vis Sci 45:1311-1315.

Baird PN, Richardson AJ, Robman LD, Dimitrov PN, Tikellis G, McCarty CA, Guymer RH (2006) Apolipoprotein (APOE) gene is associated with progression of age-related macular degeneration (AMD). Hum Mutat 27:337-342.

Beffert U, Weeber EJ, Durudas A, Qiu S, Masiulis I, Sweatt JD, Li WP, Adelmann G, Frotscher M, Hammer RE, Herz J (2005) Modulation of synaptic plasticity and memory by Reelin involves differential splicing of the lipoprotein receptor Apoer2. Neuron 47:567-579.

Beffert U, Nematollah Farsian F, Masiulis I, Hammer RE, Yoon SO, Giehl KM, Herz J (2006a) ApoE receptor 2 controls neuronal survival in the adult brain. Curr Biol 16:2446-2452.

Beffert U, Durudas A, Weeber EJ, Stolt PC, Giehl KM, Sweatt JD, Hammer RE, Herz J (2006b) Functional dissection of Reelin signaling by site-directed disruption of Disabled-1 adaptor binding to apolipoprotein E receptor 2: distinct roles in development and synaptic plasticity. J Neurosci 26:2041-2052.

Benhayon D, Magdaleno S, Curran T (2003) Binding of purified Reelin to ApoER2 and VLDLR mediates tyrosine phosphorylation of Disabled-1. Brain Res Mol Brain Res 112:33-45.

Bloomfield SA, Dacheux RF (2001) Rod vision: pathways and processing in the mammalian retina. Prog Retin Eye Res 20:351-384.

Boos R, Schneider H, Wassle H (1993) Voltage- and transmitter-gated currents of all-amacrine cells in a slice preparation of the rat retina. J Neurosci 13:2874-2888.

Borrell V, Del Rio JA, Alcantara S, Derer M, Martinez A, D'Arcangelo G, Nakajima K, Mikoshiba K, Derer P, Curran T, Soriano E (1999) Reelin regulates the development and synaptogenesis of the layer-specific entorhino-hippocampal connections. J Neurosci 19:1345-1358.

Brandes C, Kahr L, Stockinger W, Hiesberger T, Schneider WJ, Nimpf J (2001) Alternative splicing in the ligand binding domain of mouse ApoE receptor-2 produces receptor variants binding reelin but not alpha 2-macroglobulin. J Biol Chem 276:22160-22169.

Chai X, Forster E, Zhao S, Bock HH, Frotscher M (2009) Reelin stabilizes the actin cytoskeleton of neuronal processes by inducing $\mathrm{n}$-cofilin phosphorylation at serine3. J Neurosci 29:288-299.

Chen Y, Durakoglugil MS, Xian X, Herz J (2010) ApoE4 reduces glutamate receptor function and synaptic plasticity by selectively impairing ApoE receptor recycling. Proc Natl Acad Sci U S A 107:12011-12016.

D’Arcangelo G, Miao GG, Chen SC, Soares HD, Morgan JI, Curran T (1995) A protein related to extracellular matrix proteins deleted in the mouse mutant reeler. Nature 374:719-723.

Del Rio JA, Heimrich B, Borrell V, Forster E, Drakew A, Alcantara S, Nakajima K, Miyata T, Ogawa M, Mikoshiba K, Derer P, Frotscher M, Soriano E (1997) A role for Cajal-Retzius cells and reelin in the development of hippocampal connections. Nature 385:70-74.

Dulabon L, Olson EC, Taglienti MG, Eisenhuth S, McGrath B, Walsh CA, Kreidberg JA, Anton ES (2000) Reelin binds alpha3betal integrin and inhibits neuronal migration. Neuron 27:33-44.

Frotscher M (2010) Role for Reelin in stabilizing cortical architecture. Trends Neurosci 33:407-414.

Fuerst PG, Bruce F, Tian M, Wei W, Elstrott J, Feller MB, Erskine L, Singer JH, Burgess RW (2009) DSCAM and DSCAML1 function in self-avoidance in multiple cell types in the developing mouse retina. Neuron 64:484-497.

Hartveit E, Veruki ML (1997) AII amacrine cells express functional NMDA receptors. Neuroreport 8:1219-1223.

Haverkamp S, Wassle H (2000) Immunocytochemical analysis of the mouse retina. J Comp Neurol 424:1-23.

Heckenlively JR, Hawes NL, Friedlander M, Nusinowitz S, Hurd R, Davisson M, Chang B (2003) Mouse model of subretinal neovascularization with choroidal anastomosis. Retina 23:518-522.

Heynen H, van Norren D (1985a) Origin of the electroretinogram in the intact macaque eye-I. Principal component analysis. Vision Res 25:697-707.

Heynen H, van Norren D (1985b) Origin of the electroretinogram in the intact macaque eye-II. Current source-density analysis. Vision Res 25:709-715.
Hibi T, Mizutani M, Baba A, Hattori M (2009) Splicing variations in the ligand-binding domain of ApoER2 results in functional differences in the binding properties to Reelin. Neurosci Res 63:251-258.

Hiesberger T, Trommsdorff M, Howell BW, Goffinet A, Mumby MC, Cooper JA, Herz J (1999) Direct binding of Reelin to VLDL receptor and ApoE receptor 2 induces tyrosine phosphorylation of disabled- 1 and modulates tau phosphorylation. Neuron 24:481-489.

Hoe HS, Rebeck GW (2005) Regulation of ApoE receptor proteolysis by ligand binding. Brain Res Mol Brain Res 137:31-39.

Hoffman DR, Locke KG, Wheaton DH, Fish GE, Spencer R, Birch DG (2004) A randomized, placebo-controlled clinical trial of docosahexaenoic acid supplementation for X-linked retinitis pigmentosa. Am J Ophthalmol 137:704-718.

Hu W, Jiang A, Liang J, Meng H, Chang B, Gao H, Qiao X (2008) Expression of VLDLR in the retina and evolution of subretinal neovascularization in the knockout mouse model's retinal angiomatous proliferation. Invest Ophthalmol Vis Sci 49:407-415.

Jinwal UK, Trotter JH, Abisambra JF, Koren J, Lawson LY, Vestal GD, O'Leary JC, Johnson AG, Jin Y, Jones JR, Li Q, Weeber EJ, Dickey CA (2011) The Hsp90 kinase co-chaperone Cdc37 regulates tau stability and phosphorylation dynamics. J Biol Chem 286:16976-16983

Kesaniemi YA, Ehnholm C, Miettinen TA (1987) Intestinal cholesterol absorption efficiency in man is related to apoprotein E phenotype. J Clin Invest 80:578-581.

Kolb H, Famiglietti EV (1974) Rod and cone pathways in the inner plexiform layer of cat retina. Science 186:47-49.

Kurumada S, Onishi A, Imai H, Ishii K, Kobayashi T, Sato SB (2007) Stagespecific association of apolipoprotein A-I and $\mathrm{E}$ in developing mouse retina. Invest Ophthalmol Vis Sci 48:1815-1823.

Li C, Huang Z, Kingsley R, Zhou X, Li F, Parke DW, 2nd, Cao W (2007) Biochemical alterations in the retinas of very low-density lipoprotein receptor knockout mice: an animal model of retinal angiomatous proliferation. Arch Ophthalmol 125:795-803.

Malek G, Johnson LV, Mace BE, Saloupis P, Schmechel DE, Rickman DW, Toth CA, Sullivan PM, Bowes Rickman C (2005) Apolipoprotein E allele-dependent pathogenesis: a model for age-related retinal degeneration. Proc Natl Acad Sci U S A 102:11900-11905.

May P, Bock HH, Nimpf J, Herz J (2003) Differential glycosylation regulates processing of lipoprotein receptors by gamma-secretase. J Biol Chem 278:37386-37392.

McGuire BA, Stevens JK, Sterling P (1984) Microcircuitry of bipolar cells in cat retina. J Neurosci 4:2920-2938.

Niu S, Renfro A, Quattrocchi CC, Sheldon M, D’Arcangelo G (2004) Reelin promotes hippocampal dendrite development through the VLDLR/ ApoER2-Dab1 pathway. Neuron 41:71-84.

Rice DS, Curran T (2000) Disabled-1 is expressed in type AII amacrine cells in the mouse retina. J Comp Neurol 424:327-338.

Rice DS, Nusinowitz S, Azimi AM, Martinez A, Soriano E, Curran T (2001) The reelin pathway modulates the structure and function of retinal synaptic circuitry. Neuron 31:929-941.

Schmid RS, Jo R, Shelton S, Kreidberg JA, Anton ES (2005) Reelin, integrin and DAB1 interactions during embryonic cerebral cortical development. Cereb Cortex 15:1632-1636.

Sheldon M, Rice DS, D’Arcangelo G, Yoneshima H, Nakajima K, Mikoshiba K, Howell BW, Cooper JA, Goldowitz D, Curran T (1997) Scrambler and yotari disrupt the disabled gene and produce a reeler-like phenotype in mice. Nature 389:730-733.

Suetsugu S, Tezuka T, Morimura T, Hattori M, Mikoshiba K, Yamamoto T, Takenawa T (2004) Regulation of actin cytoskeleton by mDab1 through N-WASP and ubiquitination of mDab1. Biochem J 384:1-8.

Trommsdorff M, Gotthardt M, Hiesberger T, Shelton J, Stockinger W, Nimpf J, Hammer RE, Richardson JA, Herz J (1999) Reeler/Disabled-like disruption of neuronal migration in knockout mice lacking the VLDL receptor and ApoE receptor 2. Cell 97:689-701.

Wachtmeister L (1998) Oscillatory potentials in the retina: what do they reveal. Prog Retin Eye Res 17:485-521.

Weeber EJ, Beffert U, Jones C, Christian JM, Forster E, Sweatt JD, Herz J (2002) Reelin and ApoE receptors cooperate to enhance hippocampal synaptic plasticity and learning. J Biol Chem 277:39944-39952.

Zhang J, Diamond JS (2006) Distinct perisynaptic and synaptic localization of NMDA and AMPA receptors on ganglion cells in rat retina. J Comp Neurol 498:810-820. 